\title{
Alternative Housing and Care Arrangements: The Evidence
}

Confidential

Not to be cited without the permission of the authors

Robin Darton and Ann-Marie Muncer

Discussion Paper 2116/2

November 2004 
To be published in B. Roe and R. Beech (eds) Intermediate and Continuing Care: Policy and Practice, Blackwell, Oxford. 


\section{INTRODUCTION}

Internationally, demographic and cost pressures, together with rising expectations, have led to the development of new forms of housing and care services for older people. However, specialised housing in Britain dates back at least to the Middle Ages (Tinker, 1997), and a number of trade-based continuing care communities were established in the 19th and early 20th centuries (Hearnden, 1983). The post-war reconstruction of housing led to the development of sheltered housing, which still provides the majority of specialised housing for older people. The term 'sheltered housing' appears to derive from 1940's and 1950's design guidance, which recommended selecting a sheltered site (Butler et al., 1983).

Initially, sheltered housing provision grew relatively slowly, but accelerated during the 1960s and 1970s (DoE, nd). It was seen as part of a continuum, for people who did not need the degree of care provided in residential accommodation. However, Townsend (1962) viewed sheltered housing as an alternative to residential care for most residents, and the extent to which it should replace or be complementary to residential care has been a matter of debate (Butler et al., 1983). By the late 1990s, the overall levels of provision of sheltered housing dwellings and care home places were broadly similar (Audit Commission, 1998; Conway, 2000), although the contraction in care home capacity that began in 1997 (Laing and Buisson, 2003a) has been changing the balance of provision. Thus, two different forms of communal living for older people have existed side by side, differing in regulatory requirements and financial arrangements (Oldman, 2000).

By the early 1980s, there was a trend towards greater support to people in their own homes and towards the development of the concept of very sheltered housing (Butler et al., 1983). For example, Warwickshire County Council actively promoted very sheltered housing, which had enhanced design features and full-time warden cover, supplemented by domiciliary services (Reed et al., 1980), with the aim of supporting residents as they became more frail and reducing admissions to residential homes.

Very sheltered housing provision developed gradually but, more recently, local authorities have expressed increased interest in integrated care and housing as an 
alternative to care homes, particularly for physically frail older people. For example, Wolverhampton has a strategy involving the closure of local authority residential homes, and the creation of new very sheltered schemes, resource centres for community support and specialist centres for older people with mental health needs (Bailey, 2001). Such developments have been stimulated by several factors: a greater need for care and support among people in existing sheltered housing; the unpopularity of some ordinary sheltered housing schemes; poor quality local authority residential accommodation; and developments in services and buildings enabling people to age in place (Fletcher et al., 1999). Local authorities also view very sheltered housing as good value for money (Baker, 1999). Furthermore, some care homes still have shared bedrooms (Laing and Buisson, 2003a), which the moderation of the national care standards ( $\mathrm{DoH}, 2003 \mathrm{a}, \mathrm{b})$ is likely to perpetuate.

Local authorities such as Wolverhampton have viewed very sheltered housing as a means of replacing residential care by a more enabling housing and support model and philosophy, aimed at meeting the changing aspirations of older people (Fletcher et al., 1999). In contrast to care homes, very sheltered housing claims to encourage independent living, and some developments provide a wide range of facilities and stimulating environments (Oldman, 2000). It may be difficult for schemes to provide a substitute for care homes as well as a more independent living environment, but providers claim that very sheltered housing can counter the dependency and decline associated with living in care homes (Oldman, 2000). Very sheltered housing is intended to support ageing in place, although the degree to which schemes aim to provide a 'home for life' varies (Oldman, 2000). There is some evidence that very sheltered housing can accommodate people with dementia (Tinker, 1989), unless the lives of other residents appear to be affected by their behaviour (Oldman, 2000).

For owner-occupiers, entry to a care home frequently requires the sale of their home, whereas private sector sheltered housing, usually termed retirement housing, enables some housing equity to be retained. Private retirement housing developed rapidly during the 1980s, but it is very responsive to economic conditions, and declined sharply in the early 1990s (Dalley, 2001), before recovering gradually (Elderly Accommodation Counsel, 2003). 
Sheltered housing, private retirement housing and very sheltered housing schemes have usually been developed as free-standing facilities. Continuing care communities, where the housing, personal and health care needs of residents are met on one site (Hearnden, 1983), are relatively rare in Britain, but have been developed extensively in Europe and, especially, in the United States (US). Another type of combined scheme is close care, where accommodation for independent living is situated adjacent to a care home.

A number of countries in Western Europe have developed new forms of housing, often integrated with community-based services, to provide greater support and to help maintain older people in the community (Kodner, 2003). As in the United Kingdom (UK), earlier models of specialised housing have become unsuitable for current needs, expectations and levels of disability (Phillips et al., nd). Developments in other countries are informing new housing arrangements in the UK, for example co-housing (Brenton, 2002). However, these need to fit the specific economic and social context. For example, collective living arrangements are less popular in the UK (Heywood et al., 2002) or the US (Folts and Muir, 2002) than in mainland Europe.

A long-standing aim of government policy has been to enable people to live independently in their own homes (Cmnd 8173, 1981; Cm 849, 1989; Cm 4169, 1998). This contributed to a decline in support for sheltered housing and a steep reduction in the number of new developments in the 1990s (Tinker et al., 1999; Oldman, 2000). Furthermore, relatively little attention was paid to housing issues prior to the 1990 National Health Service and Community Care Act (for example: DHSS, 1981; Audit Commission, 1986; Griffiths, 1988). The 1990 Act formalised the involvement of housing authorities in assessments for community care services, but progress was unsatisfactory (Audit Commission, 1998; Harrison and Heywood, 2000; Cameron et al., 2001).

The present government supported the development of specialist, or extra care housing in guidance for establishing joint strategies for housing and community care (DoH and DoE, 1997), and reaffirmed the role of housing (Cm 4169, 1998). In 2002, plans were announced for an expansion in extra care provision (DoH, 2002a), and subsequently the Extra Care Housing Fund was created to develop innovative housing with care arrangements (DoH, nd). Further guidance was published in 2003 (ODPM, 2003). 
However, the government remained concerned that sheltered housing was being used to meet a shortfall in small, ordinary housing, and that the objectives for very sheltered housing were not being clarified before development began (ODPM, 2001).

Since sheltered housing provides the majority of specialised housing for older people, and is the forerunner of the majority of housing developments with more intensive care services, the next section of this chapter describes the types and levels of provision of sheltered housing. The chapter then describes more recent developments in extra care housing, before examining a number of important current issues, relating to costs and funding, the characteristics and needs of residents and staffing. This is followed by a discussion of continuing care or retirement communities, in particular the results from the research conducted at Hartrigg Oaks in York and the studies of retirement villages developed by the ExtraCare Charitable Trust. The development of integrated care and housing and its potential as an alternative to care home provision raises a wide range of issues, and the chapter concludes with a discussion of some of the current gaps in knowledge that need to be explored.

\section{SHELTERED AND VERY SHELTERED HOUSING}

\section{Definitions}

There has been considerable confusion about definitions of sheltered housing (Butler et al., 1983; Fletcher et al., 1999; Riseborough et al., 2001; DoH, 2003d; Laing and Buisson, 2003b).

The design guidance for post-war housing reconstruction described self-contained dwellings for able-bodied old people, and warden-supervised hostels with bed-sitting rooms, communal facilities and an alarm system $(\mathrm{MoH}$ and MoW, 1944; MoH, 1949; MLGP, 1951). Subsequently, recommendations were published for bed-sitting room flatlets with kitchen facilities, an intermediate form of accommodation (MHLG, 1958, 1960). 
In 1969, housing designed for older people was classified into two categories: selfcontained dwellings for more active older people (Category 1); and grouped flatlets for less active older people (Category 2) (MHLG, 1969). Optionally, Category 1 accommodation could include common rooms, an alarm system to communicate with a nominated person or be visible externally, and guest facilities. Category 2 accommodation was required to include self-contained accommodation for a warden, an alarm system from each dwelling to the warden and communal facilities. Consequently, there was considerable blurring between the two categories (Fletcher et al., 2001).

In 1981, all housing circulars were withdrawn (Butler et al., 1983), but the Housing Act 1985 identified specialised housing for older people as having a resident warden or the services of a non-resident warden with a call system and the use of a common room. Very sheltered housing was also termed 'Category $2 \frac{1}{2}$ ' or 'Category 2.5 ', since it fell between Category 2 sheltered housing and residential care regulated under Part III of the National Assistance Act 1948 (Tinker, 1989). McCafferty (1994) distinguished an intermediate category (Category 1.5) as housing with an alarm system and warden support, but no communal facilities, and stated that categories 1.5, 2 and 2.5 corresponded to the description in the 1985 Act. However, these categories do not appear to be completely consistent with the wording of the Act.

For the purposes of the Housing Investment Programme returns (DETR, 2000a), sheltered dwellings were specially designed or adapted with either a resident warden, an alarm system offering access to a warden with a common room close by, or conformed to the provisions of the 1985 Housing Act. However, the first two criteria appear to be sufficient to correspond directly to the Act.

Prior to the implementation of Supporting People (DSS, 1998; DETR, 2001b) in 2003, the Housing Corporation classified housing for older people as Category 1 accommodation, Category 2 accommodation, and housing for frail elderly people (Housing Corporation, 2003). The latter would include a warden or 24-hour emergency care and communal facilities, but could be either shared or self contained.

Riseborough et al. (2001) argued that the distinctions between the categories were much less straightforward than suggested by McCafferty, and did not adequately define the 
range of provision available, and also created widespread confusion among consumers. In a separate report (Fletcher et al., 2001), it was argued that Category 1 sheltered housing could provide additional choice for older people if it was clearly presented and marketed. However, although the term 'sheltered housing' often includes Category 1 accommodation, technically it should be restricted to schemes with the services of a warden and communal facilities (Audit Commission, 1998). Variations in definitions have important implications for the statistics collected on provision (Fletcher et al., 2001; Riseborough et al., 2001; Laing and Buisson, 2003b).

Riseborough et al. (2001) proposed that sheltered housing should be defined as 'Grouped housing particularly aimed at people over retirement age and at people with disabilities who are approaching retirement age' with 'a set of descriptors clarifying which design and service features are present in the scheme' (p.12). Following the implementation of Supporting People, and to improve the definitions of sheltered housing, the Housing Corporation has changed its definitions of housing for older people to distinguish housing for older people with all or some specific design features, designated supported housing for older people, and general needs housing (Housing Corporation, 2004).

\section{Private Retirement Housing}

Private retirement housing has received very little attention in the literature (Dalley, 2001). It is usually purchased on a long lease, or less often as a freehold (Laing and Buisson, 2003b). Developers of private retirement housing include for-profit and notfor-profit organisations: the term 'private' refers to the ownership of the property (Laing and Buisson, 2003b). However, some providers offer properties for purchase or rent. Private retirement housing emphasises the property and property-related services, rather than any care and support provided, but providers are increasingly developing integrated housing and care (Laing and Buisson, 2003b). 


\section{Levels of Provision}

Information on sheltered and very sheltered housing was collected on the Housing Investment Programme (HIP) returns until 2000. Subsequently, however, the forms were revised in the light of changes in government policy and to reduce the burden on local authorities (DETR, 2001a). There were approximately 500,000 units of sheltered and very sheltered housing in 2000 (see Table 1), a slight reduction from 1997 (Tinker et al., 1999). The information for very sheltered housing relates to places rather than dwellings, and thus Table 1 overstates the relative provision of very sheltered housing. However, the degree of overstatement is likely to be small. In 1990, nearly 95 per cent of category 2.5 units were bedsits or single-bed units (McCafferty, 1994). Thus, very sheltered housing accounted for less than 5 per cent of social or public sector sheltered housing in 2000. Private providers accounted for 10 per cent of the total number of units, and Registered Social Landlords (RSLs), formerly housing associations, accounted for 39 per cent.

Table 1: Sheltered and Very Sheltered Housing Provision for Older People, England, 2000

\begin{tabular}{|l|c|c|c|c|c|}
\hline & $\begin{array}{c}\text { Local } \\
\text { authority }\end{array}$ & RSLs & $\begin{array}{c}\text { Other public } \\
\text { sector }\end{array}$ & $\begin{array}{c}\text { Private } \\
\text { sector }^{3}\end{array}$ & Total \\
\hline Sheltered $^{1}$ & 244475 & 181614 & 1802 & - & 479267 \\
\hline Very sheltered $^{2}$ & 7043 & 12555 & 532 & - & 20130 \\
\hline Total dwellings & 251518 & 194169 & 2334 & 51376 & 499397 \\
\hline
\end{tabular}

Source: DETR (2000a).

Notes:

1. Sheltered housing dwellings.

2. Very sheltered places.

3. Very sheltered places in the private sector were not collected separately.

Until 1998/99, the Survey of English Housing provided information about the number of people living in sheltered housing, which was defined as accommodation with a warden (ONS, 2000). However, few units are likely to have a warden service but no alarm system. For example, in 1977 the figure was only eight per cent (DoE, nd). In 1998/99, around 600,000 people were living in sheltered housing, 86 per cent of whom were living in social or public sector schemes. 


\section{Difficult-to-Let Properties}

The recommendations contained in the early design manuals were intended to minimise the burden of housework. However, bed-sitting rooms with cramped facilities and communal bathrooms and toilets became difficult to let (Butler et al., 1983; Middleton, 1987; Tinker et al., 1995). Location, lack of a lift, overprovision in some areas and high rents are further reasons for schemes being difficult to let (Tinker et al., 1995; Nocon and Pleace, 1999). This problem is not confined to ordinary sheltered housing. Some very sheltered housing was created by upgrading ordinary sheltered schemes and, in 1994, Tinker et al. (1995) found that some very sheltered housing was difficult to let, possibly due to a dislike of shared facilities (Tinker et al., 1999). In 1990, 32 per cent of very sheltered housing units were not self-contained (McCafferty, 1994). Concern about obsolescence has led to an emphasis on flexible designs that avoid future redundancy and anticipate technological and other developments (Robson et al., 1997; Fletcher et al., 1999), that is, 'future proofing' (DoH, 2002b).

\section{EXTRA CARE HOUSING}

\section{Definitions}

Until recently, the umbrella term 'assisted living' was used for integrated housing and care in the UK (Laing and Buisson, 2003a), but it has been replaced by the term 'extra care housing' (Laing and Buisson, 2003b). Extra care housing covers a range of specialist housing models, and refers to a concept rather than a particular type of housing (Riseborough and Fletcher, 2003). Extra care housing was originally synonymous with very sheltered housing. More recently, however, retirement communities have incorporated extra care provision, and schemes for particular service user groups are being developed. There is no clear definition of extra care housing (DoH, 2003d; Laing and Buisson, 2003b), since the characteristics of extra care housing are often found in ordinary sheltered housing, and different agencies and providers have their own definitions. 
Laing and Buisson (2003b) suggest that extra care housing can be recognised by several characteristics: it is for older people; the accommodation ought to be self-contained; care can be delivered flexibly, usually by a team of staff based on the premises; communal facilities and services are available; it aims to be a home for life; and it offers security of tenure. Although the previous Housing Corporation definition included nonself-contained accommodation, developers are unlikely to build shared accommodation (Laing and Buisson, 2003b). In addition, Laing and Buisson indicate that care and support staff should be available for 24-hour care, and suggest that the requirement to have integrated care means that a single agency should be providing care to most residents. The Department of Health (DoH, 2003d) has also suggested an additional category of enhanced sheltered housing, which has additional staffing and some specialised facilities, without remodelling the building or providing full 24-hour care.

\section{Levels of Provision}

The lack of a universal definition complicates attempts to collect statistics on extra care housing. Taking a broad definition, the Elderly Accommodation Counsel identified 596 extra care schemes in England in 2003, providing around 21,000 dwellings (DoH, 2003c). However, some schemes did not provide 24-hour care, and it is likely that the estimated number will be reduced by the collection of more detailed information. The numbers were already lower than those reported in an earlier version of the directory (Laing and Buisson, 2003b). The majority of the schemes were free standing, generally for fewer than 50 residents, although some were larger, and a small number of larger care villages and details of linked care homes were also included. Previous work by the Elderly Accommodation Counsel had identified 150 close care schemes, providing an estimated 1,000 to 1,500 units of accommodation (Laing and Buisson, 2003b).

\section{Assisted Living}

In the US, assisted living refers to housing-based long-term care for frail older people who require personal care but not usually skilled nursing care (Regnier et al., 1995; Schwarz, 2001). It developed from the mid-1980s (Regnier et al., 1995), and was 
providing care for a million individuals by the late 1990s (Schwarz, 2001). Regnier et al. (1995) describe two typical resident profiles for assisted living: cognitively alert but physically frail individuals; and physically able but mentally frail individuals experiencing the first stages of dementia. The lack of alternatives to nursing homes meant that such individuals had been forced into nursing home care. However, assisted living is more readily available to middle- and upper-income individuals, while those on lower incomes have to rely on subsidised housing without care or on medicallyorientated long-term care institutions (Schwarz, 2001). In addition, increasing frailty and declining health may result in residents being asked to leave (Frank, 2001).

\section{COSTS AND FUNDING ISSUES}

The possibility of replacing care homes with extra care housing has focused interest on their comparative costs. Tinker et al. (1999) examined the resource costs of a variety of scenarios, but other studies have made contentious claims based on accounting costs (Oldman, 2000). There are also concerns that local authorities may develop extra care housing to transfer costs to social security funding (Laing and Buisson, 2003a). For example, housing benefit has enabled extra care housing to develop opportunistically (Oldman, 2000).

Netten and Curtis (2003) indicate that capital costs of local authority sheltered housing are higher than for residential care, but revenue costs are lower. Tinker et al. (1999) showed that the costs of care in different locations depend on the level and organisation of care: extra care housing was more expensive than private sector residential care, and for some individuals it was more expensive than local authority residential care. Most studies do not consider sufficiently all the factors associated with costs, specifically the contribution of informal carers and affordability (Oldman, 2000). Another factor is the potential impact on other forms of provision, for example savings to the health services from reduced admissions to hospital (Laing and Buisson, 2003b).

From 2003, Supporting People introduced new financial arrangements for statesupported tenants, in order to replace the fragmented system of funding arrangements and to overcome legal restrictions on the use of housing benefit for care services. It was 
also intended to remove the link between support and tenure. Personal care services would be provided separately following a social services or health assessment. However, providers have raised concerns about the impact on the warden service of disaggregating the service charge element from rents (Fletcher et al., 1999; Oldman, 2000). Further concerns have been raised about whether support for housing will be adequately recognised in a cash-limited scheme administered by local authorities, (Heywood et al., 2002). The government's rent restructuring policy (DETR, 2000b) has also affected relative rent levels in the local authority and RSL sectors.

The Extra Care Housing Fund (DoH, nd) has enabled a number of schemes to obtain funding. However, a large number of proposals were unsuccessful (DoH, 2004) and limits on funding have restricted the development of extra care housing (Fletcher et al., 1999). New funding opportunities using Public Private Partnerships, such as the Private Finance Initiative, are being used to develop schemes, but further development of partnerships at the commissioning and development stages and innovations in construction and remodelling will be needed to match development to demand (Fletcher et al., 1999).

Extra care or very sheltered housing enables residents to safeguard their capital and to purchase a flexible package of care on the domiciliary model, rather than a fixed quantity of care as in a care home. Whereas publicly-funded residents in care homes only retain a small personal expenses allowance, income from pensions and benefits can be used to pay the rent and personal care in extra care housing and still provide a comfortable sum to live on (Oldman, 2000). Each resident has substantially more accommodation than in a care home and the privacy and independence given by selfcontained accommodation. Although larger accommodation may appear to be more costly, Laing (2002) argues that the greater potential for alternative use suggests that long-term financing can be achieved at lower rates of return than for care home premises. Further investigation of the costs to all parties of extra care housing is vital before its role can be properly evaluated. More generally, the relative outcomes for residents need to be considered in making an overall judgement of relative costs. 


\section{THE CHARACTERISTICS AND NEEDS OF RESIDENTS}

A number of studies have collected information enabling comparisons with residential care (for example, Boldy et al., 1973; Plank, 1977; Reed et al., 1980; Baker, 1999; McCoy, nd). Providers of sheltered and very sheltered housing, mainly in the social housing sector, have also sponsored studies, principally for management purposes, which have included information about residents (for example, Fennell, 1986; Middleton, 1987; Riseborough and Niner, 1994; Bartholomeou, 1999). A small number of larger scale studies have provided more systematic comparisons of sheltered and very sheltered schemes (Butler et al., 1983; Tinker, 1989; McCafferty, 1994).

Butler et al., Tinker and McCafferty reported similar findings about the characteristics of residents in sheltered and very sheltered housing. Residents tended to be older, and were more likely to be female, to be living alone and more dependent than individuals living in ordinary housing. Equally, these characteristics also distinguished residents in very sheltered housing from those in sheltered housing, while residents in very sheltered housing were much less dependent than those in residential homes. Residents in local authority provision were more likely to have come from council housing and have been in a partly skilled or unskilled occupation than those in housing association schemes. However, it appeared that, in some cases, specialised housing was being used to respond to specific housing problems. Butler et al. and McCafferty found that sheltered housing tenants were more likely to have been living in privately-rented housing, where the standard of accommodation tended to be poorer than elsewhere, than older people as a whole. Secondly, McCafferty identified an apparent increase in the proportion of residents in sheltered and very sheltered housing with no measured dependency, as well as an increase in those with high levels of dependency.

A particular concern during the development of sheltered housing was the level of need of sheltered housing tenants and the role of the warden. In 1961, the concept of a 'balanced population' of tenants was advocated (MHLG and MoH, 1961). This was seen as necessary for tenants to provide mutual support and to reduce demands on the warden (Butler et al., 1983), although tenants have been found to provide very limited help to others (Middleton, 1987; Tinker, 1989). It was also seen as creating a fundamental contradiction about the role of sheltered housing, since the provision of 
additional services to people with lower levels of need was inequitable (Butler et al., 1983; Tinker, 1984; Middleton, 1987). Furthermore, although sheltered housing was developed to tackle both housing and care needs, it was usually allocated according to housing need and managed as housing provision (Butler et al., 1983; Tinker, 1984). At the same time, insufficient attention was given to the development of ordinary housing suitable for older people (Oldman, 1986; Middleton, 1987).

The development of extra care housing has reactivated the issue of a balanced community (Robson et al., 1997), since the principle of ageing in place may contradict the targeting of care towards the most frail, particularly where extra care is seen as an alternative to care home provision. In addition, if extra care housing incorporates higher levels of care than residents require, on average, it is difficult to justify on cost grounds (DoH, 2003d).

In the case of people with dementia, extra care housing schemes are usually able to accept people in the early stages of the disease and support people who develop dementia while they are residents (Fletcher et al., 1999). However, where the lives of other residents appear to be affected by the behaviour of residents with dementia, a move to a care home may be encouraged (Oldman, 2000). The Department of Health has also encouraged the development of pilot schemes for people with learning disabilities who can no longer be supported by their parents (DoH, 2003d).

Relatively little specialised housing has been developed specifically for older people in black and minority ethnic groups, in contrast to day care and home care services (SSI, 1998; Fletcher et al., 1999). However, the increasing number of older people from minority groups, facing different housing and social conditions (Blakemore, 2000), has led to greater concern to develop culturally appropriate forms of provision (Fletcher et al., 1999; DoH, nd).

The development of mixed tenure schemes and schemes that provide community facilities raises questions about the acceptability of the arrangements to residents. Studies in care homes have indicated tensions between long-stay residents and shortstay residents and day centre users (Allen, 1983; Wright, 1995). The design of schemes that provide community facilities needs to incorporate the principles of progressive 
privacy (Fletcher et al., 1999), for example by ensuring that there is a physical barrier between public areas and areas used solely by residents and staff.

\section{STAFFING ISSUES}

A central aspect of sheltered housing is that it is supervised by a warden, and the role, training and qualifications of wardens have received extensive examination. Traditionally, the warden has acted as a caretaker of the property and as a 'good neighbour' (Butler et al., 1983; Laing and Buisson, 2003b), although the 'good neighbour' role was rarely defined, and views of the role varied considerably (Butler et al., 1983). With increasing dependency among residents, the role of the warden became more welfare-oriented and more demanding (Laing and Buisson, 2003b). At the same time, wardens have become more professionalised, with a coordinating and enabling role (Tinker et al., 1999; Heywood et al., 2002). However, relatives and wardens remain unclear about their respective roles, and the emphasis on the enabling role can lead to a reduction in direct contact between the warden and the residents (Heywood et al., 2002).

In order to reduce costs, sheltered housing schemes are increasing the use of nonresident, peripatetic wardens (Laing and Buisson, 2003b). Some providers of very sheltered housing have replaced the warden by a scheme manager who is responsible for housing, care and support, whereas others have retained the warden role, but renamed as the estate manager, and contract out care services to separate agencies (Oldman, 2000).

The integration or separation of accommodation and care raises issues relating to costeffectiveness, registration and the delivery of care (Oldman, 2000; Heywood et al., 2002). For older people in social housing, the emphasis on residents as tenants rather than as social work clients suggests a bias towards the separation of the housing function (Tinker et al., 1999). The separation of accommodation and care, for example in schemes run by Hanover (Bartholomeou, 1999), may ensure that housing support services are given greater attention. However, there are concerns about whether this can achieve a seamless service (Oldman, 2000), particularly if there is no care team manager on site (Fletcher et al., 1999). Another reason for the separation of care is that 
the scheme would be registered as providing domiciliary care under the Care Standards Act 2000 (DoH, 2003d), whereas providing personal care would require the scheme to register as a care home (DoH, 2002c), with significant costs (Oldman, 2000).

Very sheltered housing usually has a dedicated team of care or support workers to provide 24-hour care services. When they are based on-site, these are usually sleepingin staff, although some newer schemes have night staff on duty (Fletcher et al., 1999). However, some providers only offer 24-hour cover through an alarm service. The provision of 24-hour care also raises issues about the overall size of the scheme. The size of sheltered housing schemes was often based on the maximum workload that the warden could manage (Fisk, 1986), and there were criticisms that developments were over-concentrated (Fisk, 2003). Schemes in which 24-hour care is provided would need to be sufficiently large for daytime staffing to be organised efficiently without overprovision (DoH, 2003d).

\section{RETIREMENT COMMUNITIES}

\section{Definitions}

Continuing care communities provide for a broader mix of age and dependency ranges and a wider range of communal facilities than would be feasible in a smaller development. They have been relatively rare in the UK, although a number of villages have been developed in the last 20 years. However, not all provide personal care (Laing and Buisson, 2003b).

In the US, continuing care retirement communities form part of the wider retirement community industry. The broad range of retirement communities is unique to the US, and has been attributed to the availability of land and areas with attractive climates (Streib, 2002). Retirement communities in the US date back to the 1920s, but substantial development followed the Second World War, ranging from complete new towns, such as Sun City in Arizona, to small retirement residences (Hunt et al., 1984). Many classifications of retirement communities have been proposed, but have frequently omitted precise definitions of what should be included in particular 
categories, and have ignored their dynamic nature (Hunt et al., 1984). Hunt et al. identified four types of leisure-oriented retirement community (LORCs) (Folts and Muir, 2002), which catered for predominantly healthy, often relatively young residents; and continuing care retirement centres (or communities), which catered for a mixture of healthy and frail older residents. In addition to specially-designed communities, naturally-occurring retirement communities (NORCs) can develop through the ageing of the local population or by the out-migration of younger people (Phillips et al., 2001).

In the UK, the terms 'retirement village' and 'continuing care retirement community' tend to be used interchangeably (Laing and Buisson, 2003b). However, Laing and Buisson suggest that, following US practice, the charges to residents should include insurance against future care costs for a scheme to be classed as a continuing care retirement community (Streib, 2002). There are approximately 2,000 continuing care retirement communities in the US, located in both the for-profit and the non-profit sectors (Streib, 2002). However, in the UK, only Hartrigg Oaks in York, operated by the Joseph Rowntree Housing Trust (JRHT), meets this specific definition.

\section{Hartrigg Oaks: A Continuing Care Retirement Community}

Although planning began in 1983, Hartrigg Oaks was only opened in 1998, following seven years' delay in obtaining planning permission. The development includes 152 bungalows, which can accommodate up to 247 residents, and a central building providing communal facilities and a 41-place care home (Rugg, 2000; Sturge, 2000). Residents contribute an initial capital payment or residence fee, and a monthly maintenance or community fee, and there are several payment options. The standard community fee covers care for up to 21 hours per week. Where care needs exceed this, the resident may be asked to move to the care centre (Sturge, 2000). The contract is similar to a tenancy agreement, and residents who breach it will be asked to leave. However, there is a hardship fund for residents who need financial help.

Providers managing continuing care retirement communities need actuarial estimates of health status and life expectancy, and need to predict the future finances of the community (Streib, 2002). The JRHT needed to ensure that there were groups of older 
people who would be able to afford the fees. Actuarial calculations of the likely mortality rates and care needs of residents were particularly important since residents would be relatively wealthy and have high survival rates. However, there was a lack of information about the needs of the target group of residents and a degree of uncertainty in making predictions for relatively small numbers of individuals (Rugg, 2000).

Internal monitoring (Sturge, 2000) and external evaluation (Rugg, 2000; Croucher et al., 2003) demonstrated that Hartrigg Oaks was popular, and enabled the development of an active community with numerous leisure interests. Some problems were identified with the design of the bungalows and the organisation of care. For example, low-level baths designed for ease of access were considered to be too institutional. Similarly, many residents disliked being associated with a retirement community, and the phrase 'Continuing Care Retirement Community' was removed from the entrance sign. More residents required support than had been anticipated, and the community fees had to be increased to cover increased staffing levels. However, the care home was little used for permanent stays, but more for respite and rehabilitative/intermediate care. Residents who were older or more frail tended to be less likely to participate in social activities, while the capacity to care for people with dementia was relatively limited and raised concerns about whether the scheme could provide a home for life.

The majority of continuing care retirement communities in the US and Germany are not-for-profit concerns, and residents viewed the reputation of the JRHT as a non-profit organisation as an important safeguard (Rugg, 2000; Croucher et al., 2003). Only about 25 per cent of older people were estimated to be able to afford the charges (Croucher et al., 2003), and Hartrigg Oaks is expensive until residents need the level of support that is available (Hanson, 2001). Although the level of satisfaction suggests that further schemes for people with similar income levels would be feasible (Croucher et al., 2003), there are questions about how easily the model could be replicated (Rugg, 2000). However, the high space standards, amenities and range of care services provide general lessons for all types of retirement community (Croucher et al., 2003).

Although the growth in home ownership may be expected to increase the proportion of older people who could afford the cost of developments like Hartrigg Oaks, a majority of older people are unlikely to be able to afford such schemes in the foreseeable future. 
Developments offering a range of tenures will be accessible to a much wider range of older people. In recognition of the growth in home ownership, some providers of rented schemes have considered developing mixed tenure schemes, for example the ExtraCare Charitable Trust (Appleton and Shreeve, 2003).

\section{ExtraCare Charitable Trust Developments}

The ExtraCare Charitable Trust had 19 extra care schemes in 2003, providing 958 units of accommodation (Laing and Buisson, 2003b), and further developments are in progress. Two of the schemes were retirement villages: Berryhill Retirement Village in Stoke-on-Trent consists of 148 units, and was developed for social renting; Ryfields Retirement Village in Warrington consists of 243 units, including 70 to be sold, either outright, or by using a variety of shared equity arrangements (Appleton and Shreeve, 2003). One of the Trust's earlier schemes formed part of the strategy for replacing residential care in Wolverhampton. An independent comparison of the tenants of the scheme and a comparable community sample found that the tenants had maintained their physical and mental health and social functioning, in contrast to the deteriorating functioning among the comparison group, and were more satisfied with their lives, despite being more than three years older, on average, than the comparison group (Kingston et al., 2001). Peer support and safety and security were identified as key factors in maintaining tenants' well-being. A further study of residents of Berryhill identified greater challenges in promoting the community ethos of the Trust. The facilities and activities available encouraged participation and involvement, but for residents with physical or mental health problems the environment could exacerbate their condition and lead to greater isolation (Bernard et al., 2004). The results of this study have been used in the planning and delivery of services at Ryfields (Appleton and Shreeve, 2003).

\section{GAPS IN KNOWLEDGE}

The main sources of information on the provision of extra care housing are statistical returns to the Office of the Deputy Prime Minister and the Housing Corporation, and the 
surveys conducted by the Elderly Accommodation Counsel. Laing and Buisson compile an annual report on extra care housing that draws on these sources of information, together with other national statistics, research reports and information obtained from providers. However, none of the sources of information give an overall picture (Laing and Buisson, 2003b). The collection of statistical information has been complicated by the variety of definitions used by different agencies, and it remains to be seen whether the new Housing Corporation definitions will help to clarify the position. The figures presented in Table 1 are drawn from the HIP returns for 2000, since this was the last year that this information was collected.

The national returns provide basic information about the stock of sheltered and very sheltered housing, by location and ownership. More detailed information is collected by the Elderly Accommodation Counsel on extra care housing, including information on the number of dwellings, the facilities, the support for residents, the policy on pets, the provision of meals and the types of tenure available, and is published as a directory of schemes, not as a statistical report (DoH, 2003c).

As noted above, three large-scale studies have been undertaken to provide systematic comparisons of sheltered and very sheltered schemes, but these are dated. In addition, a number of in-depth studies have been undertaken about individual developments, for example the monitoring and evaluation of Hartrigg Oaks and the studies of the schemes developed by the ExtraCare Charitable Trust. However, there has been no recent comprehensive evaluation of the new forms of provision and there has been no real attempt to assess outcomes and/or the quality of care (Oldman, 2000). Since extra care housing is being viewed as an alternative to care homes, comparative information is needed about both forms of provision, including information on costs and the characteristics of residents. Although more information is available about care homes and their residents, changes in care home provision (Darton et al., 2003) indicate that an up-to-date comparative study is needed. Information about residents is particularly important, because different forms of accommodation may be more suitable for different client groups, for example residents with mental health problems and members of black and minority ethnic groups. 
Developments in extra care have resulted in changes in the role of the warden or scheme manager, and some providers have separated the housing and care functions. In addition, the supply of care staff is a major issue for providers of all types of care services. The advantages and disadvantages of alternative staffing arrangements and their relative costs need to be investigated, as well as more general issues of staff supply, qualifications, training and reimbursement.

Extra care housing includes a wide range of types of provision, and some schemes formerly described as very sheltered housing may have more in common with care homes than retirement villages. The developments supported by the Extra Care Housing Fund will be evaluated (DoH, 2003d), but these will also need to be placed in the context of extra care developments more widely. Internationally, particularly in the US, there is a developing literature on assisted living and retirement communities, for example the volumes edited by Schwarz (2001) and Streib (2002). However, comparisons with developments in the UK need to take account of the particular economic and social circumstances of the different countries.

Extra care housing also needs to be considered in relation to housing policies more generally, and this also requires information about facilities, the characteristics of residents, costs and outcomes. Extra care housing developments that incorporate the principles of universal design, demonstrated in standards for Lifetime Homes, can provide an enabling environment in which residents can age in place (Hanson, 2001), and are examples of attempts at future proofing. The Department of Health remains concerned that extra care provision for less dependent older people is a form of overprovision. However, without a range of levels of dependency, extra care housing could become another version of a care home, with entry being delayed until few options remain for the older person. Furthermore, the ethos of extra care housing as housing would be lost.

\section{SUMMARY}

Studies of extra care housing suggest that housing-based developments can provide greater independence and a range of activities for residents. However, compared with 
ordinary sheltered housing, the number of places available in such schemes is still very small. Retirement villages or communities potentially offer a very wide range of facilities, but the number of these is extremely small, and the history of Hartrigg Oaks illustrates the practical difficulties in establishing a large-scale new development. For more dependent residents, extra care schemes have been found to provide an attractive alternative form of accommodation, but the longer-term viability and limitations of such schemes for more dependent residents need to be investigated. Similarly, the social cost of extra care housing needs proper investigation. Some extra care housing developments are taking account of the implications of the growth in owner-occupation, but there are few such schemes so far, and the range of financial products and tenure arrangements available to potential residents needs much more development. 


\section{REFERENCES}

Allen, I. (1983) Short-Stay Residential Care for the Elderly. London: Policy Studies Institute.

Appleton, N. and Shreeve, M. (2003) Now for Something Different - The ExtraCare Charitable Trust's Approach to Retirement Living. Witney: Old Chapel Publishing.

Audit Commission (1986) Making a Reality of Community Care. London: HMSO.

Audit Commission (1998) Home Alone: The Role of Housing in Community Care. London: Audit Commission.

Bailey, A. (2001) New Agenda for Older People. Wolverhampton: Wolverhampton City Council.

Baker, T. (1999) "You Have Your Own Front Door". Cambridgeshire and Peterborough Very Sheltered Housing Review. Cambridge: Cambridgeshire County Council.

Bartholomeou, J. (1999) A View of the Future: The Experience of Living in extraCare. Staines: Hanover Housing Group.

Bernard, M., Bartlam, B., Biggs, S. and Sim, J. (2004) New Lifestyles in Old Age: Health, Identity and Well-Being in Berryhill Retirement Village. Bristol: The Policy Press.

Blakemore, K. (2000) Health and social care needs in minority communities: an overproblematized issue? Health and Social Care in the Community, 8, No. 1, 22-30.

Boldy, D., Abel, P. and Carter, K. (1973) The Elderly in Grouped Dwellings: A Profile. Publication No. 3. Exeter: Institute of Biometry and Community Medicine, University of Exeter.

Brenton, M. (2002) Choosing and managing your own community in later life. In K. Sumner (ed.) Our Homes, Our Lives: Choice in Later Life Living Arrangements, 141160. London: Centre for Policy on Ageing.

Butler, A., Oldman, C. and Greve, J. (1983) Sheltered Housing for the Elderly: Policy, Practice and the Consumer. London: George Allen \& Unwin.

Cameron, A., Harrison, L., Burton, P. and Marsh, A. (2001) Crossing the Housing and Care Divide. Bristol: The Policy Press.

Care Standards Act 2000 (2000 c. 14) London: The Stationery Office.

Cm 849 (1989) Caring for People: Community Care in the Next Decade and Beyond. London: HMSO.

Cm 4169 (1998) Modernising Social Services: Promoting Independence, Improving Protection, Raising Standards. London: The Stationery Office.

Cmnd 8173 (1981) Growing Older. London: HMSO.

Conway, J. (2000) Housing Policy. London: Routledge.

Croucher, K., Pleace, N. and Bevan, M. (2003) Living at Hartrigg Oaks: Residents' Views of the UK's First Continuing Care Retirement Community. York: Joseph Rowntree Foundation. 
Dalley, G. (2001) Owning Independence in Retirement: The Role and Benefits of Private Sheltered Housing for Older People. CPA Reports 30. London: Centre for Policy on Ageing.

Darton, R., Netten, A. and Forder, J. (2003) The cost implications of the changing population and characteristics of care homes. International Journal of Geriatric Psychiatry, 18, No. 3, 236-243.

DETR (2000a) 2000 Housing Investment Programme: Operational Information. London: Department of the Environment, Transport and the Regions.

DETR (2000b) Quality and Choice: A Decent Home for All. The Way Forward for Housing. London: Department of the Environment, Transport and the Regions.

DETR (2001a) Housing Investment Programme (HIP) 2001: Guidance Notes for Local Authorities. July 2001. London: Department of the Environment, Transport and the Regions.

DETR (2001b) Supporting People: Policy into Practice. January 2001. London: Department of the Environment, Transport and the Regions.

DHSS (1981) Report of a Study on Community Care. London: Department of Health and Social Security.

DoE (no date) Report on a Survey of Housing for Old People Provided by Local Authorities and Housing Associations in England and Wales. London: Department of the Environment.

DoH (2002a) Expanded Services and Increased Choices for Older People: Investment and Reform for Older People's Social Services. Press Release 2002/0324. London: Department of Health.

DoH (2002b) Feedback on the Launch of the Housing Learning and Improvement Network on Friday, 22 November 2002 at the ICC, Birmingham. London: Department of Health.

DoH (2002c) Supported Housing and Care Homes: Guidance on Regulation. August 2002. London: Department of Health.

DoH (2003a) Amended National Minimum Standards for Care Homes. Press Release 2003/0070. London: Department of Health.

DoH (2003b) Care Homes for Older People: National Minimum Standards. London: The Stationery Office.

DoH (2003c) Extra Care Housing Directory. Change Agent Team, Housing Learning \& Improvement Network, and Elderly Accommodation Counsel. London: Department of Health.

DoH (2003d) Extra Care Housing for Older People: An Introduction for Commissioners. London: Department of Health.

DoH (2004) 'Independence not Dependence' - New Extra Care Housing Places for Older People Announced. Press Release 2004/0070. London: Department of Health.

DoH (no date) Developing and Implementing Local Extra Care Housing Strategies. London: Department of Health.

DoH and DoE (1997) Housing and Community Care: Establishing a Strategic Framework. London: Department of Health. 
DSS (1998) Supporting People: A New Policy and Funding Framework for Support Services. London: Department of Social Security.

Elderly Accommodation Counsel (2003) Housing and Care Homes for Older People in England: Key Data Report 2003. London: Elderly Accommodation Counsel.

Fennell, G. (1986) Anchor's Older People: What Do They Think? A Survey among Tenants Living in Sheltered Housing. Oxford: Anchor Housing Association.

Fisk, M.J. (1986) Independence and the Elderly. Beckenham: Croom Helm.

Fisk, M.J. (2003) Social Alarms to Telecare: Older People's Services in Transition. Bristol: The Policy Press.

Fletcher, P., Riseborough, M., Humphries, J., Jenkins, C. and Whittingham, P. (1999) Citizenship and Services in Older Age: The Strategic Role of Very Sheltered Housing. Beaconsfield: Housing 21.

Fletcher, P., Riseborough, M. and Mullins, D. (2001) What Future for Category 1 Sheltered Housing? Updating Ideas, Policy and Practice. Housing Research at CURS, No. 13. Birmingham: School of Public Policy, University of Birmingham.

Folts, W.E. and Muir, K.B. (2002) Housing for older adults: new lessons from the past. Research on Aging, 24, No. 1, 10-28.

Frank, J. (2001) How long can I stay?: The dilemma of aging in place in assisted living. In B. Schwarz (ed.) Assisted Living: Sobering Realities, 5-30. New York: The Haworth Press.

Griffiths, R. (1988) Community Care: Agenda for Action. A Report to the Secretary of State for Social Services. London: HMSO.

Hanson, J. (2001) From 'special needs' to 'lifestyle choices': articulating the demand for 'third age' housing. In S.M. Peace and C. Holland (eds) Inclusive Housing in an Ageing Society: Innovative Approaches, 29-53. Bristol: The Policy Press.

Harrison, L. and Heywood, F. (2000) Health Begins at Home: Planning at the HealthHousing Interface for Older People. Bristol: The Policy Press.

Hearnden, D. (1983) Continuing Care Communities: A Viable Option in Britain? CPA Reports 3. London: Centre for Policy on Ageing.

Heywood, F., Oldman, C. and Means, R. (2002) Housing and Home in Later Life. Buckingham: Open University Press.

Housing Act 1985 (1985 c. 68) London: HMSO.

Housing Corporation (2003) Scheme Development Standards, 5th ed. London: Housing Corporation.

Housing Corporation (2004) The Housing Corporation's Definitions of Housing Association Supported Housing and Housing for Older People. Housing Corporation Regulatory Circular 03/04. London: Housing Corporation.

Hunt, M.E., Feldt, A.G., Marans, R.W., Pastalan, L.A. and Vakalo, K.L. (1984) Retirement Communities: An American Original. New York: The Haworth Press.

Kingston, P., Bernard, M., Biggs, S. and Nettleton, H. (2001) Assessing the health impact of age-specific housing. Health and Social Care in the Community, 9, No. 4, 228-234. 
Kodner, D.L. (2003) Long-term care integration in four European countries: a review. In J. Brodsky, J. Habib and M. Hirschfeld (eds) Key Policy Issues in Long-Term Care, 91-138. Geneva: World Health Organization.

Laing, W. (2002) Calculating a Fair Price for Care: A Toolkit for Residential and Nursing Care Costs. Bristol: The Policy Press.

Laing and Buisson (2003a) Care of Elderly People: Market Survey 2003, 16th ed. London: Laing and Buisson.

Laing and Buisson (2003b) Extra-Care Housing Markets 2003/4. London: Laing and Buisson.

McCafferty, P. (1994) Living Independently: A Study of the Housing Needs of Elderly and Disabled People. Housing Research Report, Department of the Environment. London: HMSO.

McCoy, P.V. (no date) Census of Residential Accommodation, 1980: Interim Report Sheltered Housing. Ipswich: Social Services Department, Suffolk County Council.

Middleton, L. (1987) So Much for So Few: A View of Sheltered Housing, 2nd ed. Occasional Papers 3. The Institute of Human Ageing. Liverpool: Liverpool University Press.

MHLG (Ministry of Housing and Local Government) (1958) Flatlets for Old People. London: HMSO.

MHLG (Ministry of Housing and Local Government) (1960) More Flatlets for Old People. London: HMSO.

MHLG (Ministry of Housing and Local Government) (1969) Housing Standards and Costs: Accommodation Specially Designed for Old People. Circular 82/69. London: HMSO.

MHLG and MoH (Ministry of Housing and Local Government and Ministry of Health) (1961) Services for Old People. Joint Circular 10/61 and 12/61. London: HMSO.

MLGP (Ministry of Local Government and Planning) (1951) Housing for Special Purposes. Supplement to the Housing Manual 1949. Report of the Housing Manual Sub-Committee of the Central Housing Advisory Committee under Extended Terms of Reference. London: HMSO.

MoH (Ministry of Health) (1949) Housing Manual 1949. London: HMSO.

MoH and MoW (Ministry of Health and Ministry of Works) (1944) Housing Manual 1944. London: HMSO.

National Assistance Act 1948 (11 \& 12 Geo. VI c. 29) London: HMSO.

National Health Service and Community Care Act 1990 (1990 c. 19) London: HMSO.

Netten, A. and Curtis, L. (2003) Unit Costs of Health and Social Care 2003. Canterbury: Personal Social Services Research Unit, University of Kent.

Nocon, A. and Pleace, N. (1999) Sheltered housing and community care. Social Policy and Administration, 33, No. 2, 164-180. 
ONS (Office for National Statistics) (2000) Housing in England 1998/99. A Report of the 1998/99 Survey of English Housing carried out by the Social Survey Division of ONS on behalf of the Department of the Environment, Transport and the Regions. London: The Stationery Office.

ODPM (2001) Quality and Choice for Older People's Housing: A Strategic Framework. London: Office of the Deputy Prime Minister.

ODPM (2003) Preparing Older People's Strategies: Linking Housing to Health, Social Care and Other Local Strategies. London: Office of the Deputy Prime Minister.

Oldman, C. (1986) Housing policies for older people. In P. Malpass (ed.) The Housing Crisis, 174-199. Beckenham: Croom Helm.

Oldman, C. (2000) Blurring the Boundaries: A Fresh Look at Housing and Care Provision for Older People. Brighton: Pavilion Publishing (Brighton) Ltd.

Phillips, J., Bernard, M., Biggs, S. and Kingston, P. (2001) Retirement communities in Britain: a 'third way' for the third age? In S.M. Peace and C. Holland (eds) Inclusive Housing in an Ageing Society: Innovative Approaches, 189-213. Bristol: The Policy Press.

Phillips, J., Means, R., Russell, L. and Sykes, R. (no date) Broadening Our Vision of Housing and Community Care for Older People: Innovative Examples from Finland, Sweden and England. Kidlington: Anchor Research.

Plank, D. (1977) Caring for the Elderly: Report of a Study of Various Means of Caring for Dependent Elderly People in Eight London Boroughs. Research Memorandum 512. London: Greater London Council.

Reed, C.A., Faulkner, G.J. and Bessell, R. (1980) Your Own Front Door: A Study of Very Sheltered Housing in Warwickshire, 1979-80. Warwick: Warwickshire County Council Social Services Department.

Regnier, V., Hamilton, J. and Yatabe, S. (1995) Assisted Living for the Aged and Frail: Innovations in Design, Management, and Financing. New York: Columbia University Press.

Riseborough, M. and Fletcher, P. (2003) Extra Care Housing - What is it? Factsheet No. 1. Housing Learning and Improvement Network. London: Department of Health.

Riseborough, M. and Niner, P. (1994) I Didn't Know You Cared! A Survey of Anchor's Sheltered Housing Tenants. Oxford: Anchor Housing Trust.

Riseborough, M., Fletcher, P. and Mullins, D. (2001) The Case for a Common Currency: Clearer Definitions and Descriptions for Sheltered and Supported Housing. A Discussion Paper for the Housing Corporation. Housing Research at CURS, No. 6. Birmingham: School of Public Policy, University of Birmingham.

Robson, D., Nicholson, A.-M. and Barker, N. (1997) Homes for the Third Age: A Design Guide for Extra Care Sheltered Housing. London: E \& FN Spon.

Rugg, J. (2000) Hartrigg Oaks: The Early Development of a Continuing Care Retirement Community, 1983-1999. York: Centre for Housing Policy, University of York.

Schwarz, B. (2001) Introduction. In B. Schwarz (ed.) Assisted Living: Sobering Realities, 1-4. New York: The Haworth Press. 
SSI (Social Services Inspectorate) (1998) 'They Look After Their Own, Don't They?' Inspection of Community Care Services for Black and Ethnic Minority Older People. London: Department of Health.

Streib, G.F. (2002) An introduction to retirement communities. Research on Aging, 24, No. 1, 3-9.

Sturge, M. (2000) Continuing Care Retirement Communities in the UK: Lessons from Hartrigg Oaks. York: Joseph Rowntree Foundation.

Tinker, A. (1984) Staying at Home: Helping Elderly People. London: HMSO.

Tinker, A. (1989) An Evaluation of Very Sheltered Housing. London: HMSO.

Tinker, A. (1997) Older People in Modern Society, 4th ed. London: Longman.

Tinker, A., Wright, F. and Zeilig, H. (1995) Difficult to Let Sheltered Housing. London: HMSO.

Tinker, A., Wright, F., McCreadie, C., Askham, J., Hancock, R. and Holmans, A. (1999) Alternative Models of Care for Older People. The Royal Commission on Long Term Care (1999) With Respect to Old Age: Long Term Care - Rights and Responsibilities. Research Volume 2. Cm 4192-II/2. London: The Stationery Office.

Townsend, P. (1962) The Last Refuge: A Survey of Residential Institutions and Homes for the Aged in England and Wales. London: Routledge \& Kegan Paul.

Wright, F. (1995) Opening Doors: A Case Study of Multi-Purpose Residential Homes. London: HMSO. 